\title{
CONCEPÇÕES SOBRE MEIO AMBIENTE DE ALUNOS DO ENSINO FUNDAMENTAL EM BELÉM-PA: ESTUDO DE CASO COM A E.E.E.F.M. PROF. GOMES MOREIRA JUNIOR
}

Bianca Venturieri ${ }^{1}$

Alzira Santana ${ }^{2}$

Resumo: Essa pesquisa teve como objetivo investigar as concepções sobre meio ambiente de estudantes do Ensino Fundamental e a partir dessa análise apresentar a importância da preservação do meio ambiente em um ambiente escolar. Para sistematização da pesquisa foi utilizado a aplicação de um questionário e a elaboração de um desenho que representasse a concepção de meio ambiente para os 50 alunos do $6^{\circ}$ e $7^{\circ}$ ano do Ensino Fundamental nos meses de agosto e setembro de 2014 na E.E.E.F.M. Prof. Gomes Moreira Junior em Belém (PA). De acordo com a análise dos dados foi verificado que a maioria dos alunos percebe que só os animais, as plantas, fazem parte do meio ambiente e uma pequena parcela entende que o homem também faz parte do meio ambiente e infelizmente o mesmo acaba destruindo esse meio que ele tanto necessita. Também foi verificado que esse assunto é exclusivamente trabalhado pelo professor de Ciências sendo fundamental, portanto que esse tema seja trabalhado em toda a sua complexidade por toda a comunidade escolar.

Palavras-chave: Concepções; Meio Ambiente; Alunos.

1Universidade do Estado do Pará. E-mail: bianca.venturieri@gmail.com 2Universidade do Estado do Pará. E-mail: alzirasantana2009@bol.com.br Revbea, São Paulo, V. 11, No 1: 234-245, 2016. 


\section{Introdução}

A Educação Ambiental tem papel de construir valores sociais, conhecimentos, habilidades, atitudes e competências voltadas para a conservação do meio ambiente. Sua concepção pode ser colocada em pratica por meio formal, dentro da escola, bem como de modo informal, através dos meios de comunicação. Ambos os processos têm em comum a ideia de que é necessário formar cidadãos sensibilizados capazes de tomar decisões conscientes para a vida. Quando o ser humano reflete sobre essa relação, procura o entendimento de suas concepções e se questiona sobre seu lugar no ambiente percebido, tornando possível a avaliação de suas ações sobre o mesmo (MARINS et al., 2004).

Com isso, pesquisas avaliando a concepção ambiental dos indivíduos podem também ser instrumentos educativos e transformadores desde que propiciem as condições para reflexão do próprio indivíduo. Nesse contexto, conforme pressupõem Fontana et al. (2002), as concepções ambientais podem revelar abrangência, abrigando elementos naturais, culturais, políticos, econômicos e sociais, ou reducionismo, excluindo o homem da condição de parte do ambiente.

Além disso, é comum as pessoas conceberem que a natureza é o ambiente, necessitando de apreço, respeito preservação, ou que um lugar onde se quer viver igualmente configura um ambiente, entendendo-se, portanto, que sua moradia e a vizinhança, assim como seus espaços de estudo, lazer e demais fatores do cotidiano, integram sua totalidade (SAUVÉ, 1997).

Por outro lado, a dimensão ambiental na educação, em muitos casos, se reduz à incorporação de temas e princípios ecológicos às diferentes matérias de estudo e a um tratamento geral dos valores ecológicos, em vez de tentar traduzir o conceito de ambiente e o pensamento da complexidade na formação de novas mentalidades, conhecimentos e comportamentos (LEFF, 2005). Para Meyer (1991), para se iniciar um trabalho na área de Educação Ambiental, é preciso começar fazendo com que os alunos expressem a leitura que fazem do ambiente em que vivem. Assim, os alunos falam do vivido, do observado, fazendo com que haja a construção do conhecimento por parte dos alunos e não uma imposição por parte do professor.

A inexistência de uma definição consensual de meio ambiente, inclusive dentro da esfera científica, propicia enquadrá-lo no âmbito da representação social (REIGOTA, 2002). Logo, interagir com concepções ambientais nos posiciona perante símbolos, valores, regras de conduta, saberes, superstições interagindo com outras concepções oriundas da realidade (GUEDES, 2003). Krasilchik (1986) comenta que para uns o meio ambiente é apenas um tema 
neutro de estudo, visando ao conhecimento direto e íntimo da natureza, enquanto que, para outros, são incluídos o elemento humano e os fatores que interferem em suas relações com o meio ambiente. Para Azevedo (1999), ao buscar conhecer essas representações, o professor pode confrontar as ideias dos alunos com aquilo que ensina, levantando questões importantes que possibilitem refletir sobre suas práticas educativas, verificando a necessidade ou não de trabalhar na perspectiva da superação de visões ambientais eventualmente distorcidas que os alunos possam ter.

Portanto, conhecer a representação dos alunos sobre as questões relativas ao ambiente poderá auxiliar o professor a entender como eles as estão captando, interpretando e agindo em sua realidade próxima, já que essas representações são fundamentais na formação de opiniões e no estabelecimento de atitudes individuais e coletivas. No entanto, como são dinâmicas, é importante identificá-las, para que sejam trabalhadas tanto com os alunos quanto nas relações escola-comunidade (CRESPO,1998).

$\mathrm{Na}$ escola, os conteúdos de meio ambiente devem ser integrados ao currículo através da transversalidade, pois serão tratados nas diversas áreas do conhecimento de modo a impregnar toda a prática educativa e, ao mesmo tempo criar uma visão global e abrangente da questão ambiental (TOMAZELLO, 2001). Contudo e imprescindível trabalhar na perspectiva da transversalidade, apontada neste documento que enfatiza como estratégia metodológica, a utilização de projetos, revela-se um desafio que as escolas vêm enfrentando como muitas dificuldades.

Diante das reflexões anteriormente abordadas essa pesquisa teve como objetivo investigar as concepções sobre meio ambiente de estudantes do Ensino Fundamental e a partir dessa análise apresentar a importância da preservação do meio ambiente em um ambiente escolar. O processo de alerta, é o primeiro passo para alcançar o pensamento sistêmico. Consequentemente espera-se uma mudança de atitude de todos os envolvidos na pesquisa. Assim sendo entendemos que a escola é o espaço social e o local onde o aluno deve ser sensibilizado para as ações ambientais e por consequente fora do âmbito escolar ele será capaz de dar sequência ao seu processo de socialização.

\section{Material e métodos}

\section{Período e local do estudo}

O trabalho foi desenvolvido no período de agosto a setembro de 2014 na Escola Estadual de Ensino Fundamental e Médio (EEEFM) Prof. Gomes Moreira Junior em Belém (PA). Para sistematização da pesquisa foi utilizado a aplicação de um questionário e a elaboração de um desenho que representasse a concepção de meio ambiente para 50 alunos do $6^{\circ}$ e $7^{\circ}$ ano do Ensino Fundamental.

O questionário teve perguntas qualitativas e quantitativas sobre a preservação do meio ambiente. Os desenhos foram utilizados como forma de 
estimular os alunos a expressarem suas concepções de meio ambiente, por intermédio da percepção visual e intuitiva. A pesquisa foi desenvolvida em três momentos a seguir:

$1^{\circ}$ momento: aplicação de questionários sobre preservação do meio ambiente com os alunos do $6^{\circ}$ e $7^{\circ}$ ano.

$2^{\circ}$ momento: levantamento das concepções dos alunos sobre o meio ambiente através dos desenhos onde os mesmos ilustraram a concepção sobre o meio ambiente através de formas de figuras.

3 momento: após a coleta dos dados foi realizada a análise dos dados coletados que foram divididos em quatro categorias baseadas nas proposições de Reigota (1991), Tamaio (2000) e Fontana et al. (2002) (Quadro 1).

Quadro 1: Divisão de categorias que classificam as concepções de meio ambiente.

\begin{tabular}{|l|l|}
\hline Categorias & Descrição \\
\hline Romântica & $\begin{array}{l}\text { Elabora uma visão de mãe natureza. Aponta a grandiosidade da } \\
\text { natureza, sempre harmônica, enaltecida, com equilíbrio e beleza. O } \\
\text { homem não está inserido neste processo. }\end{array}$ \\
\hline Reducionista & $\begin{array}{l}\text { Traz a ideia de que o meio ambiente refere-se estritamente aos } \\
\text { aspectos físicos naturais, como a água, o ar, as rochas excluindo } \\
\text { o ser humano de todas as suas produções. }\end{array}$ \\
\hline Abrangente & $\begin{array}{l}\text { Define o meio ambiente de uma forma mais ampla. Abrange uma } \\
\text { totalidade que inclui os aspectos naturais e os resultantes das das } \\
\text { atividades humanas. }\end{array}$ \\
\hline Sócio ambiental & $\begin{array}{l}\text { Apresenta o homem e a paisagem construída como elementos } \\
\text { constitutivos da natureza. Postula uma compreensão de que o } \\
\text { homem apropria-se da natureza e muitas vezes o homem surge } \\
\text { como destruidor e responsável pela degradação ambiental. }\end{array}$ \\
\hline
\end{tabular}

\section{Resultados e discussão}

\section{Preservação do meio ambiente na visão dos alunos}

Dos 50 questionários aplicados $60 \%$ dos alunos definiram o meio ambiente como a natureza os animais e as plantas; $20 \%$ destes afirmaram 0 meio ambiente como o lugar onde devemos preservar; $15 \%$ o lugar onde vivemos e 5\% como o homem destruindo a natureza. Malafaia e Rodrigues (2009) na sua pesquisa identificaram que $63,4 \%$ dos alunos pesquisados não se consideram parte integrante do meio ambiente, assim como considerado pela maioria dos brasileiros, de acordo com o estudo do Ministério do Meio Ambiente (CRESPO,1998).

$\mathrm{Na}$ pergunta sobre o que é Educação Ambiental $50 \%$ dos alunos definiram que é educar e ensinar a como cuidar do meio ambiente; $17 \%$ responderam que é o respeito a preservar o meio ambiente e $33 \%$ reponderam que é manter o ambiente limpo sem desmatamento e poluição. Quando questionados se o ser humano depende do meio ambiente, $77 \%$ dos alunos 
responderam que sim e depende dele para sobreviver; $7 \%$ responderam que sim é ele que devemos cuidar; $10 \%$ como sim para depender para respirar; $3 \%$ como sim ele vive no meio ambiente, e 3\% responderam que não dependem dele e o homem só faz destruir.

Em um estudo desenvolvido por Brondani e Heinzel (2010) com relação à conscientização ambiental, grande parte dos alunos acredita que os problemas ambientais afetam seu dia-a-dia, e que preservando o meio ambiente, sua vida e das gerações futuras será melhor. Nesse contexto, segundo Reigota (1998, p.12), a EA aponta para propostas pedagógicas centradas na conscientização, mudança de comportamento, desenvolvimento de competências, capacidade de avaliação e participação dos educandos. Para Pádua e Tabanez (1998, p. 9), a EA propicia o aumento de conhecimentos, mudança de valores e aperfeiçoamento de habilidades, condições básicas para estimular maior integração e harmonia dos indivíduos com o meio ambiente.

Segundo Guimarães (2002, p.31) é preciso estar claro que conscientizar não é simplesmente transmitir valores "verdes" do educador para o educando; essa é a lógica da educação "tradicional"; é, na verdade, possibilitar ao educando questionar criticamente os valores estabelecidos pela sociedade, assim como os valores do próprio educador que está trabalhando em sua conscientização. É permitir que o educando construa o conhecimento e critique valores com base em sua realidade.

Ao serem questionados sobre quais ações do homem contra a natureza, $20 \%$ definiram desmatamento e poluição dos rios; $28 \%$ como desmatamento e queimadas; $34 \%$ desmatamento e extinção de animais e $18 \%$ lixo nas ruas e fumaça dos carros. De acordo com o trabalho desenvolvido por Godoy et al. (2008), foi apontado pelos autores que os alunos são capazes de identificar os principais problemas ambientais. Na ocasião, ao considerarem a aprendizagem baseada em problemas como uma estratégia de ensino, os autores verificaram que os discentes investigados se referiram à diversos problemas ambientais a serem enfrentados pelos administradores das cidades. Os itens mais citados foram: "poluição atmosférica", "poluição dos lençóis freáticos", "poluição dos rios" e "poluição por resíduos químicos".

Quando perguntamos qual relação do homem como o meio ambiente, $48 \%$ responderam que o homem necessita do meio para sobreviver e $52 \%$ responderam que 0 homem vem destruindo a natureza. Também foi investigado se o tema já tinha sido trabalhado em sala de aula pelos professores e $57 \%$ dos alunos investigados afirmaram que esse assunto já foi trabalhado em sala de aula, 15\% responderam que essa temática não foi vista em sala de aula e $28 \%$ não souberam responder.

Destes $57 \%$ de alunos que responderam que já viram esse assunto ser trabalhado em sala de aula $100 \%$ dos mesmos apontaram que foi desenvolvida essa temática nas aulas de Ciências o que podemos constatar que essa temática não é vista de maneira interdisciplinar e nem de forma transversal por essa escola com sugere os Parâmetros Curriculares Nacionais (PCN"s) visto 
que a questão ambiental vem sendo considerada cada vez um tema urgente e importante para a sociedade (BRASIL, 1997).

\section{Concepções dos alunos sobre o meio ambiente}

Conforme discutido recentemente por De Oliveira e Gonçalves (2007), o termo "meio ambiente" constantemente utilizado tanto em meios de comunicação como nos discursos políticos, livros didáticos e outras fontes, demonstram uma grande diversidade de conceitos, possibilitando diferentes interpretações, muitas vezes, influenciadas pela vivência pessoal, profissional e pelas informações veiculadas na mídia. As ilustrações a seguir estão exemplificando as concepções de meio ambiente que foram divididas em quatro categorias:

\section{Categoria I: Romântica}

Nas representações sociais dos alunos sobre o meio ambiente os estudantes designaram a natureza como plantas, animais, rios correspondendo $70 \%$ das representações. O meio ambiente está ligado a natureza os animais e rios, sem o homem está presente de forma completamente intocável (Figura 1). Para Tamaio (2000), esta concepção é fortemente influenciada pela mídia. Nos principais veículos são observadas imagens de pássaros, árvores, flores e borboletas, tipicamente "românticas".

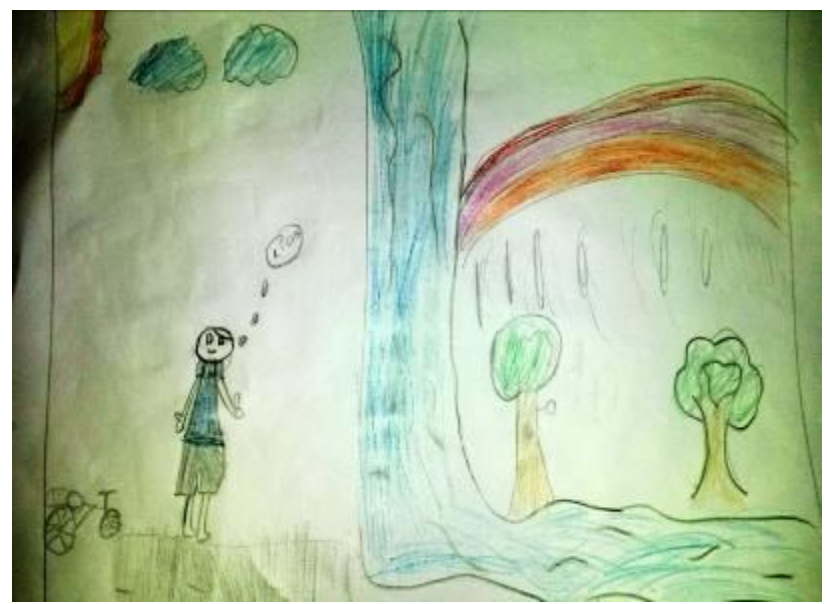

Figura 1: llustração do aluno exemplificando a categoria I. Fonte: Alzira Santana.

\section{Categoria II: Reducionista}

Observar-se nesta categoria que os alunos relacionaram a natureza intacta sem a presença do homem e dos animais correspondendo $12 \%$ das representações ligando o meio ambiente as florestas destacando as árvores (Figura 2). Esses resultados estão de acordo com o estudo desenvolvido por Hoefel et al. (2004), no qual os autores investigaram as concepções sobre a natureza e sustentabilidade de moradores da Região Bragantina em São 
Paulo, onde foi verificado que a concepção de meio ambiente está relacionada basicamente a uma visão conservacionista da natureza.

Costa et al. (2006), investigando a inserção da Educação Ambiental na prática pedagógica, na visão de alunos dos cursos técnicos no Rio Grande do Norte, identificaram entre outros aspectos, que mais da metade dos alunos investigados possui uma concepção de meio ambiente "reducionista". Molin et al. (2007) também verificaram que a concepção de meio ambiente revelada por estudantes de diferentes níveis de ensino está relacionada com uma visão naturalista de meio ambiente. Segundo esse estudo a concepção "reducionista" apresentada por muitos alunos, independentemente dos diferentes níveis de ensino, está relacionada diretamente com a vertente ecológica presente em muitos livros didáticos, onde modelos tradicionais do processo ensino aprendizagem ainda persistem.

Para Meyer (2008) os livros didáticos e as estórias infanto-juvenis estão recheados de representações sobre o meio ambiente natural e, especialmente, nos livros didáticos há uma predominância na visão utilitária, manipulativa e antropocêntrica, desconsiderando-se os conceitos fundamentais de ecologia. Ainda segundo a autora a natureza representada didaticamente aparece como coisa isolada, ausente de relações sócio históricas construídas e de processos ecológicos em curso.

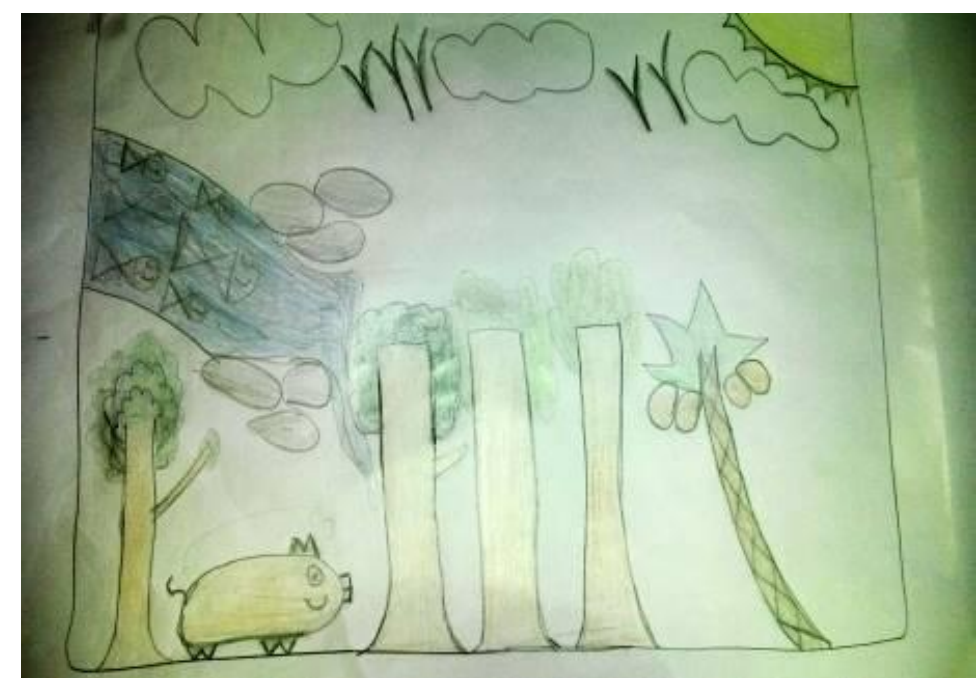

Figura 2: llustração do aluno exemplificando a categoria II. Fonte: Alzira Santana.

\section{Categoria III: Abrangente}

Nesta categoria $12 \%$ dos alunos representaram em suas ilustrações sobre o meio ambiente o lugar onde vivemos, marcada através das casas e incluindo a figura do homem ao fazer parte dessa natureza (Figura 3). Esta concepção remete a uma forma mais ampla e complexa de enxergar o meio ambiente. Nota-se a abrangência não apenas dos aspectos naturais, mas, também, os resultantes das atividades humanas, resultando na interação de fatores biológicos, físicos e econômicos. 


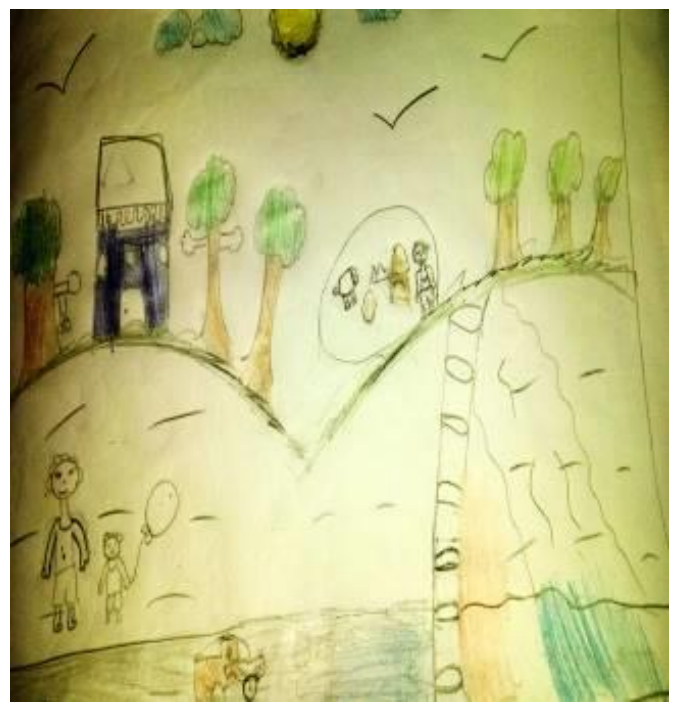

Figura 3: Ilustração do aluno exemplificando a categoria III. Fonte: Alzira Santana.

\section{Categoria IV: Sócio ambiental}

A representação colocando o homem como agente transformador do meio ambiente foi expressa por $6 \%$ dos alunos através das suas ações do desmatamento, acúmulo de lixo nas ruas, rios e extinção de animais (Figura 4). A seguir a fala do aluno representando também esse conceito:

"'Degradação, porque tudo está poluído o ar, os rios, as águas por isso que quando chove, chove muito e quando fez calor, faz muito calor é tudo em exagero!"

No estudo de Guimarães (2002), o qual envolveu professores foi evidenciado que a visão do processo de modernização está sempre associada à agressão humana sobre o meio ambiente, fato este atrelado à concepção "socioambiental" de meio ambiente, onde o ser humano aparece, em muitas vezes, como destruidor do meio.

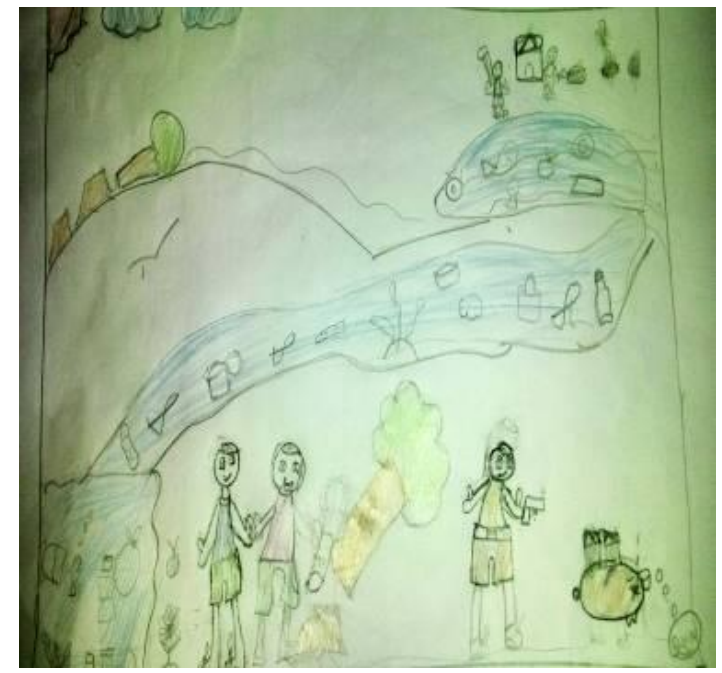

Figura 4: Ilustração do aluno exemplificando a categoria IV. Fonte: Alzira Santana. 


\section{Conclusões}

Este trabalho conclui que a maioria dos alunos percebe que só os animais, as plantas e a natureza, fazem parte do meio ambiente, uma pequena parcela entende que o homem também faz parte do meio ambiente e infelizmente o mesmo acaba destruindo esse meio que ele tanto necessita.

A forma com que a mídia, a sociedade e a escola- nos quesitos docentes, livros didáticos e paradidáticos- tratam essa questão constituem como possíveis motivações à solidificação da concepção de natureza intocada pelos discentes. A dicotomia cartesiana entre o homem e a natureza ainda continua a impregnar o conceito de meio ambiente com a sua redução à dimensão naturalista, isto é, fauna, flora, ar e água ou simplesmente quando se confunde a problemática ambiental com poluição (BRÜGGER, 1999).

Também foi constatado que a escola não desenvolve um trabalho interdisciplinar e nem de forma transversal sobre as principais temáticas e problemas ambientais sendo o conteúdo trabalhado quase exclusivamente pelo professor da disciplina de Ciências. Por isso é fundamental que esse tema seja trabalhado em toda a sua complexidade. Sugere-se, portanto que a escola comece a trabalhar na perspectiva de inserir a dimensão ambiental no currículo, numa perspectiva de um trabalho interdisciplinar, para que 0 conhecimento escolar se aproxime do cotidiano das crianças e adolescentes.

É importante reafirmar que, perante a complexidade das questões ambientais, as práticas educativas não podem deixar de buscar a aproximação com ideias, crenças, valores e atitudes dos envolvidas no processo educativo. Considerando as rodas de conversa um importante recurso didático, acreditamos que, desde que devidamente planejadas pelo professor, poderão trazer para a escola as diferentes dimensões da questão ambiental e os debates, diariamente travados na sociedade, a respeito das relações do homem com o ambiente. Para isso, devemos ressaltar que o diálogo não pode ser entendido apenas como uma técnica para aprofundar as relações entre os estudantes, mas que é algo intrínseco ao ser humano que, por natureza, é comunicativo e histórico (FREIRE, 2003 ; DAMKE, 1995).

Dessa forma, as rodas de conversa apresentaram a importante possibilidade de conhecermos contradições, oposições e conflitos inerentes aos processos que envolvem a vida das pessoas em seu meio. Isso pode exigir uma dedicação extra por parte daqueles educadores que buscam estabelecer, mediante diálogo, práticas pedagógicas comprometidas.

Outro recurso didático que pode ampliar a visão dos alunos com relação as temáticas ambientais é a utilização de jogos didáticos. De acordo com Kishimoto (2008) os jogos bem elaborados levam os jogadores a um envolvimento intenso, permite um ambiente menos formal para ação pedagógica, e proporciona ao aluno um momento prazeroso para 0 aprendizado. Considerando também que o lúdico é um eficiente recurso que auxilia no desenvolvimento da criatividade dos indivíduos. Assim as 
metodologias lúdicas favorecem a construção de novos conhecimentos e a sensibilização para os problemas ambientais (RIZZO, 2012).

Percebendo a eficácia do desenvolvimento de propostas pedagógicas lúdicas, o presente trabalho propõe desenvolver atividades associando os recursos como as rodas de conversa e a utilização de jogos didáticos em um trabalho continuo de Educação Ambiental com o intuito de promover a sensibilização na comunidade escolar para a problemática da conservação do meio ambiente formando assim indivíduos preocupados com o meio ambiente e que vão levar esses valores ao longo da vida.

\section{Referências}

BRASIL. Parâmetros Curriculares Nacionais. Secretaria de Educação Fundamental. Brasília: MEC/SEF, 1997.

BRONDANI, C.J.; HENZEL, M.E. Análise sobre a conscientização ambiental em escolas da rede municipal de ensino. Revista Brasileira de Educação Ambiental (RevBEA), v. 5, n. 1, p. 37-44, 2010.

BRÜGGER, P. Educação ou adestramento ambiental? Florianópolis: Letras Contemporâneas, 1999.

COSTA, A.P.B., PAIVA, M.S.D., FILGUEIRA, J.M. 2006. A inserção da Educação Ambiental na prática pedagógica: uma análise segundo a visão dos alunos dos cursos técnicos integrados do CEFET-RN. HOLOS, 22:62-73.

CRESPO, $\mathrm{S}$. et al. $\mathrm{O}$ que o brasileiro pensa do meio ambiente, do desenvolvimento e da sustentabilidade. Rio de Janeiro: MAST/ISER/MMA/MCT, v. 110, 1998.

DE OLIVEIRA BEZERRA, T.M.; GONÇALVES, A.A.C. Concepções de meio ambiente e Educação Ambiental por professores da Escola Agrotécnica Federal de Vitória de Santo Antão-PE. Biotemas, v. 20, n. 3, p. 115-125, 2007.

DAMKE, I.R. O processo do conhecimento na Pedagogia da Libertação: as idéias de Freire, Fiori e Dussel. Petrópolis: Vozes, 1995.

DIAS, G.F. Educação Ambiental: Princípios e Práticas. 2.ed. São Paulo: Gaia, 1993.

FONTANA, K. B. et al. A concepção de meio ambiente de alunos do curso de pedagogia a distância e a importância da mediação tecnológica: dificuldades e perspectivas. Disponível em: $<$ http://virtual.udesc.br/html/artigos professores/profs ema.htm>. Acesso em: 20 abr. 2014.

FREIRE, P. Pedagogia do oprimido. 36. ed. Rio de Janeiro: Paz e Terra, 2003.

GIL, A.C. Como elaborar projetos de pesquisa. 3. ed. São Paulo: Atlas, 1995. 
GODOY, C.E.C., SANTOS, C.G.B., CORREIA, P.R.M. (2008). A aprendizagem baseada em problemas e a introdução de conceitos químicos nas aulas de ciências no ensino fundamental II. Anais do XIV Encontro Nacional de Ensino de Química, 2008, Curitiba. Curitiba: UFPR.

GONÇALVES, CW. P. Os (des)caminhos do meio ambiente. 10. ed. São Paulo: Contexto, 2002. (Temas Atuais).

GUIMARÃES, M. Diagnóstico da percepção sócio-ambiental de Professores em Xerém (D.Caxias/RJ) e as relações com o processo de modernização. Anais do I Encontro da Associação Nacional de Pós Graduação e Pesquisa em Ambiente e Sociedade, 2002. Indaiatuba. Indaiatuba: ANPPAS, 2002.

GUARIM, V.L.M.S. Barranco Alto: uma experiência em Educação Ambiental. Cuiabá: UFMT, 2002. 134 p.

HOEFFEL, J.L. et al. Concepções e percepções da natureza na Área de Proteção Ambiental do Sistema Cantareira. Anais do Congresso Brasileiro de Unidades de Conservação, 4, 2004, Curitiba. Curitiba: Fundação O Boticário de Proteção à Natureza; Rede Nacional Pró Unidades de Conservação, v. I, p. 346-356, 2004.

KRASILCHIK, M. Educação Ambiental na escola brasileira passado, presente e futuro. Ciência e Cultura, São Paulo, v. 38, n. 12, p. 1958-1961, 1986.

INÁCIO, C. D. et al. O lixo nosso de cada dia: o que fazer? In: KINDEL, E.A.I.; SILVA, F.W.; SAMMARCO, Y.M. (org). Educação Ambiental: vários olhares e várias práticas. Porto Alegre: Mediação, 2004. p. 85 - 88.

LEFF, E. Saber ambiental: Sustentabilidade, Racionalidade, Complexidade, Poder. Petrópolis: Ed. Vozes, 2005.

KISHIMOTO, T. M. Brincar e suas teorias. São Paulo: Pioneira Thomson Cengage Learning Editores, 2008.

MALAFAIA, G.; DE LIMA RODRIGUES, A. S. Percepção ambiental de jovens e adultos de uma escola municipal de ensino fundamental. Revista Brasileira de Biociências, v. 7, n. 3, 2009.

MARINS, A. et al. Propostas de Atividades integradas no Ensino Fundamental. In: KINDEL, Eunice Aita Isaia; SILVA, Fabiano Weber e SAMMARCO, Yanina Micaela (org). Educação Ambiental: vários olhares e várias práticas. Porto Alegre: Mediação, 2004. p. 79-84. 238

MEYER, M.A.A. Educação Ambiental: uma proposta pedagógica. Em Aberto: 10 (49):41-46, 1991.

MEYER, M. Ser-tão natureza: a natureza em Guimarães Rosa. Belo Horizonte. Editora UFMG, 2008.

MOLIN, R.F.; PASQUALI, E.A.; VALDUGA, A.T. Concepções de meio ambiente formulados por estudantes de diferentes níveis de ensino. Anais do VIII Congresso de Ecologia do Brasil, 2007, Caxambu. Anais... Caxambu (MG), p. 1-2, 2007.

Revbea, São Paulo, V. 11, № 1: 234-245, 2016. 
MORAES, A. Meio Ambiente e Ciências Humanas. São Paulo: HUCITEC, 1994.

PÁDUA, S.; TABANEZ, M. Educação Ambiental: caminhos trilhados no Brasil. São Paulo: Ipê, 1998.

REIGOTA, M. Desafios à Educação Ambiental escolar. In: JACOBI, P. et al. (orgs.). Educação, meio ambiente e cidadania: reflexões e experiências. São Paulo: SMA, 1998. p. 27-32.

RIZZO, G. O Lúdico como promoção do aprendizado através dos jogos socioambientais, integrando a Educação Ambiental formal e não formal. Revista Eletrônica Mest.Educ.Ambient. v.22, 2012.

SAUVÉ, L. Educação Ambiental e desenvolvimento sustentável: uma análise complexa. Revista do Programa de Pós-graduação em Educação da UFMT, Mato Grosso, v. 006, n. 10, Jul/Dez 1997. Disponível em: http:// www.ufmt.br/revista/arquivo/rev10/educação ambiental e desenvolvim.html.

TAMAIO, I. A Mediação do Professor na Construção do Conceito de Natureza: Uma experiência de Educação Ambiental na Serra da Cantareira e Favela do Flamengo-São Paulo/SP. Dissertação de Mestrado em Educação da UNICAMP, 2000.

TOMAZELLO, M.G.C.; FERREIRA, T.R.C. Educação Ambiental: que critérios adotar para avaliar a adequação pedagógica de seus projetos?. Ciência \& Educação (Bauru), v. 7, n. 2, p. 199-207, 2001.

TOMMASI, L.R. Estudo de impacto ambiental. São Paulo: CETESB e ERRAGRAPH, 1994.

VERNIER, J. O meio ambiente. Campinas -SP: Papirus, 1994. 